\title{
Right Posterior Atrioventricular Artery
}

National Cancer Institute

\section{Source}

National Cancer Institute. Right Posterior Atrioventricular Artery. NCI Thesaurus. Code C102341.

The arterial branch between the right posterior descending artery segment and the first right posterolateral segment. 